\title{
Letter
}

\section{A wise nurse can manage a paper protocol but prefers intelligent technology}

\author{
Mathijs Vogelzang ${ }^{1}$, Felix Zijlstra ${ }^{2}$, Maarten WN Nijsten ${ }^{1}$
}

${ }^{1}$ Surgical ICU, University Medical Center Groningen, University of Groningen, Groningen, The Netherlands

${ }^{2}$ Department of Cardiology, University Medical Center Groningen, University of Groningen, Groningen, The Netherlands

Corresponding author: Mathijs Vogelzang, m.vogelzang@chir.umcg.nl

Published: 13 November 2007

Critical Care 2007, 11:423 (doi:10.1186/cc6169)

This article is online at http://ccforum.com/content/11/6/423

(C) 2007 BioMed Central Ltd

See related letter by de Graaf et al., http://ccforum.com/content/11/5/421, and related research by Shulman et al., http://ccforum.com/content/11/4/R75

We were surprised to read the letter "Tight glycaemic control: intelligent technology or a nurse-wise strategy?" by de Graaff and colleagues [1]. In this letter, the use of complex protocols for tight glucose control is questioned, and a strategy as used in Leuven is proposed: based on nurses' experience, guided with only a few very simple guidelines.

Glucose control is not simple but complex. This complexity is underscored by major problems that have been encountered with respect to safety and efficiency. Many factors are known to influence glucose control. Standardizing glucose control has been found to improve both safety and the efficiency of glucose control [2]. Moreover, results obtained with unstandardized treatment protocols as proposed by de Graaff et al. should be interpreted with great caution, as the exact characteristics of the therapy are unknown. We agree with de Graaff et al. that paper protocols can become too complex and may result in bad compliance, efficiency and safety.

Computer protocols are generally easy to follow and require fewer glucose measurements than paper-based protocols [35]. In our own three-year experience, nurses - both novice and experienced - are very pleased with the efficient process a computer provides. Still, we also value wise nurses and allow our computer protocol to be overridden when needed.

Abandoning advanced standardized therapy in favor of relying on human decision-making would clearly be a step backward in our view. The current " 5 million lives campaign" by the Institute for Healthcare Improvement calls for a $50 \%$ reduction of harm related to high-alert medications (including insulin) focusing on standardization strategies to reduce the chance of human error [6]. In our opinion, a computer program recommending an insulin level, and seeing to it that glucose gets checked in time is the most standardized, effortless, safe and efficient form of glucose control currently available.

\section{Competing interests}

The authors declare that they have no competing interests.

\section{References}

1. de Graaff MJ, Spronk PE, Schultz MJ: Tight glycaemic control: intelligent technology or a nurse-wise strategy? Crit Care 2007, 11:421.

2. Kanji S, Singh A, Tierney M, Meggison H, Mclntyre L, Hebert PC: Standardization of intravenous insulin therapy improves the efficiency and safety of blood glucose control in critically ill adults. Intensive Care Med 2004, 30:804-810.

3. Rood E, Bosman RJ, van der Spoel Jl, Taylor P, Zandstra DF: Use of a computerized guideline for glucose regulation in the intensive care unit improved both guideline adherence and glucose regulation. J Am Med Inform Assoc 2005, 12:172-180.

4. Vogelzang M, Zijlstra F, Nijsten MW: Design and implementation of GRIP: a computerized glucose control system at a surgical intensive care unit. BMC Med Inform Decis Mak 2005, 5: 38.

5. Hovorka R, Kremen J, Blaha J, Matias M, Anderlova K, Bosanska L, Roubicek T, Wilinska ME, Chassin LJ, Svacina S, Haluzik M: Blood glucose control by a model predictive control algorithm with variable sampling rate versus a routine glucose management protocol in cardiac surgery patients: a randomized controlled trial. J Clin Endocrinol Metab 2007, 92:2960-2964.

6. Federico F: Preventing harm from high-alert medications. Jt Comm J Qual Patient Saf 2007, 33:537-542. 